\title{
CLINICAL AND BACTERIOLOGICAL STUDY OF ACUTE DIARRHOEA IN CHILDREN
}

Haricharan. K. R¹, Shrinivasa. B. M², Vatsala Kumari³.

1. Assistant Professor, Department of Pediatrics, AIMS, B.G. Nagar, Mandya

2. Assistant Professor, Department of Community Medicine, AIMS ,Mandya

3. Professor, Department of Pediatrics, SSMC, Tumkur

\section{CORRESPONDING AUTHOR:}

Dr. Haricharan.K.R.

Prakash Sadana

$1^{\text {st }}$ Cross; B.G. Layout

Mandya, Karnataka: 571401

E-mail: dr.haricharan@gmail.com

\section{HOW TO CITE THIS ARTICLE:}

Haricharan. K. R, Shrinivasa. B.M, Vatsala Kumari. "Clinical and Bacteriological Study of Acute Diarrhoea in Children". Journal of Evolution of Medical and Dental Sciences 2013; Vol2, Issue 23, June 10; Page: 42294237.

ABSTRACT: OBJECTIVES: To know the hospital prevalence and clinical features of acute diarrhoea and describe the common bacterial pathogens isolated in these cases of diarrhoea in children. MATERIALS AND METHODS: A cross sectional study was carried out in children with acute diarrhea between 1 month to 12 years of age at Shree Siddhartha Medical College Hospital, Tumkur from November 2007 to August 2009.After detailed history and examination, stool samples were collected and subjected to microscopic examination and culture and sensitivity. The data thus collected was analysed. RESULTS AND CONCLUSION: Acute diarrhea accounted for $10.12 \%$ (95\% CI 8.98, 11.26) percent of total admissions to pediatric ward. The prevalence of diarrhea peaks in children aged 7-24 months (the usual weaning period) and then decreases with increasing age. The analysis of clinical presentation revealed that vomiting and fever were frequent accompaniments of diarrhoea. Artificially fed children were affected more often than exclusively breast-fed ones. Varying grades of PEM was present in majority of the study cases. Most of the cases had some dehydration. In majority of study cases enteropathogenic bacteria were isolated; among which E. coli was the commonest. Most of the isolates were sensitive to Gentamicin and Amikacin. Bacteriological study and sensitivity pattern helps us to identify the most prevalent organism in the locality and to select the most appropriate drug and thus reducing the cost of treatment. Appropriate fluid and antibiotic management resulted in prompt recovery.

KEY WORDS - Acute diarrhoea, Stool culture, Dehydration.

INTRODUCTION: Diarrhoea ranks among top three killers of pediatric subjects in developing world. Globally around one billion episodes of illness and 3-5million deaths occur as a result of diarrheal disease each year1 ${ }^{1}$.Eight out of ten of these deaths occur in first two years of life ${ }^{2}$.

In developing countries, on an average every child suffers3.3 episodes of diarrhoea per year, but in some areas the average exceeds nine episodes per year ${ }^{3}$. In India, children under 5 years of age 
suffer from 2-3 episodes of diarrhoea annually 4 . In India 17\% of all deaths in indoor patients are diarrhoea related 5 . The high incidence of morbidity and mortality in diarrhoea is related to malnutrition, poverty, poor education, low socio-economic status, poor sanitary conditions, and trends of early breast milk substituent and bottle-feeding. Repeated attacks of diarrhoea also aggravate the compromised nutritional status of under privileged children, with a consequent heightened susceptibility to infectious diseases. Hence, diarrhoea is an important contributing factor for malnutrition, which in turn predisposes the child to further diarrhoea, thereby initiating a vicious cycle 6 .This, necessitates periodic assessment of bacteriologic patterns of diarrhoea and therapeutic trials not only to ensure effective therapy, but also to forestall its dreaded complications. With this background, we conducted a study with the objective to know hospital prevalence and clinical features of acute diarrhoea and describe the common bacterial pathogens isolated in these cases of diarrhoea in children.

MATERIAL AND METHODS: Over a period of 22 months, from November 2007 to August 2009, children between 1month to 12 years of age with diarrhea admitted to Shree Siddhartha medical college and hospital, Tumkur were assessed using a question.150 cases were included in the study .All hospitalised children between 1month to 12years of age presenting with acute diarrhoea and fulfilling the following inclusion and exclusion criteria were included in the study.

\section{INCLUSION CRITERIA:}

(a) Abrupt onset of four or more loose stools per day.

(b) Less than 14 day's duration.

(c) Age between 1 month to 12 years.

\section{EXCLUSION CRITERIA:}

(a) All cases who received antibiotics before collection of stool samples were excluded Method of data collection

1. A detailed history was taken and clinical examination performed as per the proforma

2. An evaluation of degree of dehydration was done according to the proforma.

3. Two samples of stool were collected one sample in a sterile bottle for microscopic examination, the other for culture sensitivity study .The stool samples were submitted to the laboratory for analysis within 5 minutes of sample collection.

MICROBIOLOGICAL METHODS: Fresh stool samples were obtained from each patient before initiation of therapy and transported immediately for detection of established enteropathogens using standard techniques. A battery of culture media including Mac Conkeys agar, deoxycholate agar, Xylose-lysine deoxy cholate agar and salmonella differential agar were used. The isolates were identified by standard methods and were tested for their susceptibility to various antimicrobials by disc diffusion techniques.

STATISTICAL ANALYSIS: Qualitative data are expressed as percentages with 95\% Confidence Interval $(95 \% \mathrm{CI})$ and quantitative data presented as mean with standard deviation.

All tests were done using SPSS .16 Software. 
RESULTS: During 22 months of study period, the total numbers of cases admitted to the paediatric ward was 2807. Among them gastroenteritis occurred in 284 cases in children between 1 month to 12years. This makes hospital prevalence of gastroenteritis as $10.12 \%$ (95\% CI 8.98, 11.26).Among these 150 cases were taken for the study according to the inclusion and exclusion criteria. Demographic factors (Table 1and Table2)In the present study the maximum number of cases of diarrhoea occurred in first 24 mo of life 107 (71.3\%) followed by 24 mo to 60 months (15.3\%) and 6to12yrs (13.3\%).

The male to female ratio was 1: 0.85 .Majority of the children (63.33\%) less than 24 months where on breast feeds combined with artificial feeds. Exclusive Breast-feeding was given in $14.66 \%$ of the cases and only artificial feeds were given in $22 \%$ of the cases. In the present study $(51.33 \%)$ of the patients had varying grades of malnutrition, Grade I (28.66\%) and Grade II(14\%) were the most common types seen in present study.

Hydration status (Table 3)

Some dehydration was present in $80 \%$ of the cases and $14 \%$ had severe dehydration and $6 \%$ had no dehydration. Majority $(55.83 \%)$ of patients having moderate dehydration had 912stools/day. In this study the association between frequency of loose stools and severity of dehydration was statistically significant $(\mathrm{x} 2=14.0, \mathrm{df}=1, \mathrm{p}=0.001)$

Stool examination \& culture (Table 4\&5)

Microscopic examination of stool was carried out soon after admission. Fresh stool was taken and was examined under microscope with saline, iodine preparations. Pus cells $>10 / \mathrm{HPF}$ was seen in $31.33 \%$ of the cases, and RBC's were seen in $14 \%$ of the cases. A.duodenale ova was present in 1 of the cases. Cyst of E. histolytica was seen in 1 case. Reducing substances (above 0.5\%) in the stool were present in $14.66 \%$ of cases diarrhoea, acidic $\mathrm{pH}(<5.5)$ was present in $10.6 \%$ of the cases.

Stool culture for bacteria was carried out in all the study cases, and was positive in $50.66 \%$ (95\% CI 42.48, 58.83) of the cases. Escherichia coli were found to be the predominant organism accounting for $42.66 \%(95 \%$ CI $34.57,50.74)$ of the cases. Salmonella was isolated from $3.3 \%$ of cases. Klebsiella $2.66 \%$ and Shigella $2 \%$ of the cases. In $49.34 \%$ of the remaining cases, no enteropathogenic bacteria could be isolated. Among the culture positive cases 33 patients (43.42\%) had fever at the time of admission and 31 children (41.68\%) had verifying grades of malnutrition. Pus cell's > 10 / HPF in stools were present in 28(36.84\%) of the culture positive cases.

DISCUSSION: Diarrhoea in the paediatric population is one major cause of mortality globally and more so in the developing countries.

General prevalence

The prevalence of gastroenteritis in the present study was $10.11 \%(95 \%$ CI 8.98, 11.26) of total admissions. Patel B.D (1953)7, Pavri KM (1953) ${ }^{8}$, Manchanda SS and Arora NN (1958) ${ }^{9}$, Udani PM et al (1968) ${ }^{10}$, Khanduja PC and S.K.Bhargava et al (1969) ${ }^{11}$, Srivastava J.R (1968) ${ }^{12}$, Behera S.K et al $(1980)^{13}$ reported prevalence of $17.5 \%, 22.5 \%, 18 \%, 17.46 \%, 5.5 \%, 24.6 \%$ o and $11.3 \%$ respectively.

The prevalence of diarrheal disorders in children as seen in the above studies varies roughly from $5.5 \%$ to $24.6 \%$. Most diarrheal episodes occur during the first 2 years of life, and the incidence of acute diarrhoea below 2 years was $87 \%$. The high incidence of diarrheal disease in the 
first 2 years of life is probably related to faulty weaning, unhygienic handling and storage of milk and food, higher incidence of parental infection, malnutrition, development of mouthing habits at this age as suggested by Khanduja et $\mathrm{al}^{11}$ and Sood $\mathrm{S}^{14}$. To these factors can be added immaturity of the immune system of the body rendering it susceptible to an attack by the enteric pathogens, especially in association with malnutrition.

\section{SEX DISTRIBUTION}

In the present study the male to female ration was $1: 0.85$. Many others have reported no sex difference. As a matter of fact, it is difficult to conceive of any valid explanation for a higher male incidence, except that males are more prone to all infections. It could possibly be attributed to our unfavourable social outlook, ignoring and neglecting, the ailments of female children and bringing mostly the boys to the hospital. There is a representation bias of boys in hospital.

Sanitation

Poor sanitation leading to face-oral spread was noted in majority of the cases. Only $32.67 \%$ of the families were using sanitary latrines while the remaining $67.55 \%$ of the patients practiced open air defecation. Jagvir Singh et al 16 and Deivanayagam N et al 18 reported that $26.1 \%$ and $38.15 \%$ of the patients respectively were using sanitary latrines. Improper disposal of excreta results in water pollution, food contamination and propagation of flies thus leading to disease transmission.

The higher incidence in tap water users may be explained by the fact that water, despite being available from a safe source can became contaminated during the process of storage and further utilization. Most often the water and sewage lines run side by side and the lines may leak and the drinking water may gel contaminated with sewage water. Water from shallow bore wells which serve a large rural population is often contaminated if the area within 15 meters is not kept pollution free. Municipal tap water may not be properly treated and chlorinated. In the present study more than half of the patients (61\%) belonged to class III to class IV of modified BJ. Prasad's classification. Sood ${ }^{14}$ reported that $60 \%$ of the cases of diarrhoea occurred in low socio economic group.

The higher incidence in lower socioeconomic status may be due to poor sanitation, unhygienic practices, malnutrition, illiteracy etc.

Diarrhea

The average duration of diarrhoea before admission was 2.26 days. Varsha Aminet.al (1995) ${ }^{17}$ reported that the duration of diarrhoea before admission was less than 24 hours in $45.5 \%$ whereas Fukunda M.Juan et al (1995) and Karmarkar DB et al (1983) ${ }^{15}$ reported 68\% and 77\% respectively. In the present study $26 \%$ of the patients presented with diarrhoea of less than 24 hours duration. The mean frequency of diarrhoea before admission in present study was 9.02 stools per day. However Chaomin Wan et al 199919 and Anthony et al reported a mean frequency of 15.166 and $13.09+\ldots .94$ stools per day respectively.

The consistency of stools in our series varied from watery stools to semisolid stools. Majority of the cases had watery stools (84\%) and 16\% had semisolid stools. Similar results were noted by Naruka et al (1974), Reddiah VP et al 19914, Deivanayagam et al $1994^{18}$ and Kamala CS et al $1996^{21}$, who quoted figures of $83 \%, 76.6 \%, 86.137 \%, 91.84 \%$ respectively. 
No definite and accurate correlation can be made between the consistency or frequency of stools and the severity of the disease. This is because, the child who passes only 4-6 stools a day and large quantity each time may be severely dehydrated than the one who passes 8-10 stools, but small quantities each time. But if a child is passing stools more frequently and in large quantity each time, the severity of illness naturally increases.

\section{HYDRATION STATUS}

In the present study $80 \%$ of the patients had some dehydration, $6 \%$ had no dehydration and $14 \%$ severe dehydration. From this it cannot be said with certainty that some dehydration is common, because the case study was on hospital admissions and the proportion of study was small and this cannot be compared to larger group of gastroenteritis.

Our observations are nearly in concordance with those of T.S. Daral et al $(1985)^{28}$ who reported some dehydration in 76.5\%. Majority (52.66\%) of the moderately dehydrated cases had frequency of loose stools ranging from 9-12 stools per day. But from this no conclusion can be drawn because frequency of loose motion is not the criteria but it is the amount of fluid and electrolyte loss per attack which influences dehydration for which we need pre-checked weight. This is not applicable to most of the cases in our study where the previous weight was not recorded or maintained due to ignorance and illiteracy in our community.

\section{STOOL MICROSCOPY}

In our study stool examination revealed pus cells in $31.33 \%$ of the cases and RBC's were seen in $14 \%$ of the cases. These results are nearly in concordance with those of Naruka et al who reported pus cells in $43 \%$ and $\mathrm{RBC}$ in $16 \%$ of their cases.

Stool Culture

In the most carefully conducted studies of acute diarrheal diseases in different parts of the world, enter pathogenic bacteria have been detected in from 30 to 67\% (Prakash et al 196326; Dose et al 198322; Maya et al 197723; Cravioto et al 198824; A.R. Ghosh et al 199125) .

The different organisms isolated were Esch. coli (42.66\%); Salmonella (3.3\%); Klebsiella $(2.66 \%)$ and Shigella (2\%) in our study. But it is important to note that isolation of bacteria from the stools of patients does not establish an etiological relationship; and the diarrhoea in a bacterial carrier may not be caused by the pathogen isolated.

Escherichia coli:

In our study E. coli were isolated in $42 \%$ of the cases. Recognised classes of Escherichia coli (EPEC, ETEC, EHEC, EAEC, and EIEC) were not isolated due to lack of facility in the institution. However the presence of EPEC in apparently healthy children has been well documented. Some studies have shown that 8 - 12\% of apparently healthy children of this age are group excrete EPEC (Feldman et al 197027).

\section{SALMONELLA:}

Salmonella (non-typhoidal) was isolated in 3.3\% patients in present study. In all these 3 cases, the history, clinical picture and stool examination did not vary as to show a distinct or different clinical entity of Salmonellosis and it was not possible to differentiate these cases from others, until the stool culture was studied and identified a Salmonellosis 
Klebsiella:

This is also a ubiquitous organism which is isolated in a large proportion of both diarrhoeal and non diarrhoeal stools.

In our series these were isolated in $2.66 \%$ of the cases and are nearly in concordance with Maiya et $\mathrm{al}^{23}$ who isolated them in $2 \%$ of the cases.

Outcome

None of the patients in this study died in the course of disease or due to dyselectrolytemia. In our study there was no mortality mainly because our study comprised of a small group of patients and because when compared to other studies the children in this trial had a shorter duration of diarrhoea before admission and only $14 \%$ had severe dehydration and individuals with systemic infections or other disease were excluded. So the prevalence of prognostic indicators of poor outcome was lower than other studies. There was a rapid initiation of treatment on admission that included correction of dehydration and immediate introduction of feeds.

CONCLUSION: After studying 150 cases of acute diarrhoea we came to the following conclusions regarding the clinical features and bacteriological profile.

1. The incidence was more during first 24 months of life $(71.33 \%)$

2. There was no sex predilection in our study

3. The occurrence was more in children who have been weaned $(63.33 \%)$ than those who were exclusively breast fed.

4. More than half of patients (59\%) belonged to class III and IV of modified BJ. Prasad classification.

5. Majority (51.33\%) had varying grades of malnutrition. Grade I (28.66\%) and Grade II (14\%) were most common grades in present study.

6. Enteropathogenic bacteria could be isolated from $50.66 \%$ of cases of which E.coli constituted 42.66\%, Salmonella 3.3\%, Klebsiella2.66\% and Shigella2\%.

7. The Majority (70\%) of isolates were sensitive to Gentamycin and Amikacin.

LIMITATIONS: Recognised classes of Escherichia coli (EPEC, ETEC, EHEC, EAEC and EIEC) were not isolated due to lack of facility in the institution.

\section{BIBLIOGRAPHY:}

1. Gupte S, Abrams RC, Abhram A. Rehydration therapy in acute diarrheal disease: Recent advances in paediatrics, Gupte Suraj. $1^{\text {st }}$ ed. vol-15, New Delhi: Jaypee Brothers Medical publishers Ltd; 2005. P 37-51.

2. Survey of Causes of Death (Rural) - Annual Report, 1996, Office of Registrar General of India, New Delhi.

3. National family health survey (NHFS-2, 1998-99), India chapter-6, Mortality, morbidity \& immunisation, International institute for population sciences, Mumbai; 2000; 178-235.

4. Reddiah VP, Kapoor SK. Epidemiology of Diarrohea and its Implications for Providing Services. Indian J Pediatr 1991; 58: 205 -8.

5. Park K; Parks textbook of preventive and social medicine.19th ed .Jabalpur: 
Banarasidas bhanot publishers; 2007. p183.

6. World Health Organization. Readings on diarrhoea : Student manual $1992 \mathrm{pp} 3$

7. Patel. B .D. Acute diarrhoea in Children. Indian J Ch Hlth, 1953; 2: 353.

8. Pavri, K.M. Infantile diarrhea. IBID 1953; 343.

9. Manchanda SS and Arora NN. Acute gastroenteritis in infants and young children with special reference to some aetiological factors. Indian J. Pediat 1958; 25: 559.

10. Udani PM, Shah PM, Mukherjee S, Panvalkar RS, Kumbhat MM, Deshpande SN. Some trends in treatment of acute diarrhoea in infancy. Indian Pediat 1968; 5: 1

11. Khanduja PC, Bhargava SK: Etiological aspects of diarrhoea in infants and children under 5yrs.Indian J pediatrics 1969; 36: 237.

12. Shrivatsava JR. Acute diarrhoea in childhood- clinical and bacteriological study' Indian J Pediatr 1968; 35: 244

13. Behra SK, Mahapatra SS. Incidence and mortality of hospitalised diarrhoea cases'. Indian pediatrics 1980; 17: 607-2

14. Sood S. Etiology of diarrhoea in infancy. Indian J. Ch.Hlth, 1963; 12: 727

15. Cardenas Victor . Cholera in Riohacha, Columbia, 1992. Bulletin of pan America health organisation.1993;2(4): 313-29

16. Singh Jagaveer. 'Epidemiology and transmission of vibrio cholera 01 and 0139 in delhi in 1993'. Journal of diarrhoeal disease research. 1996 Sep; 14(3): 182-6

17. Amin Varsha, Patvari AK, Kumar Girish, Anand VK, Divan Meena, Pesin Sunil. 'Clinical profile of cholera in young children, hospital based report'. Indian J Pediatr 1995 July ; 32: 755-61

18. Devignam N, Mala N, Shafi Ahmad, Jagdish Shankar 'Measles associated diarrhea and pneumonia in south India'. Indian Pediatr 1994; 31: 35

19. Chaomin Wan, Michael R Phillips, Michael J Dibley, ZhengluLis Randomised trial of different rates of feeding in acute diarrhoea. Arch Dis Child 1999; 81:487-91.

20. Samantray JC, Mahapatia LN, Bhan MK. "Study of Rotavirus diarrhoea in a North Indian Community". Indian Pediatrics 1982; 9: 761 - 6.

21. Kamala CS, Vishwanathakumar HM, Shetti PM, Anand N. "Management of Diarrhoea in a DTU. Indian Pediatrics 1996; 33: 856 -9.

22. Sen D, Saha MR,M Niyogi SK, Balakrish Nair G, De SP Uaila P, et al. Aetiological studies on hospital in-patients with acute diarrhoea in Calcutta". Transmissions of the Royal Society of Tropical Medicine and Hygiene 1983; 77: 212 - 214.

23. Maiya PP, Pereira SM, Mathan M, Bhat P, Albert MJ and Baker SJ. Aetiology of acute gastroenteritis in infancy and early childhood in southern India. Arch of Dis in Child 1977; 52: 482 - 5.

24. Cravioto A, Reyes RE, Ortega R, Fernandez G, Hernandez R and Lopez D. Pro spective study of diarrhoeal disease in a cohort of rural Mexican Children: incidence and isolated pathogens during the first two years of life. Epidemiology and Infection 1988; 101: 123- 34.

25. Ghosh AR, Nair GB, Dutta P, Pal SC and Sen D. Acute diarrhoeal diseases in infants aged below six months in hospital in Calcutta, India, an aetiological study. Transactions of the Royal Society of Tropical Medicine and Hygiene 1991; 85: 796 - 98. 
26. Prakash O, Prakash CV, Amma E and Kalra SL. Microbial flora in cases of infantile diarrhoea in Delhi. Indian Journal of Medical Sciences 1963; 17; 486-90.

27. Feldman RA, Bhat $P$ and Ramath RR. Infection and disease in a group of South Indian families IV. Bacteriologic methods and a report of the frequency of enteric bacterial infection in Pre-school children. American Journal of Epidemiology' 1970; 92:367375.

28. Daral TS, Singh HP, Sachdev HSP, Manmohan ,Mathur M, Bhargav SK et al. Acute dehydrating diarrhoea- Clinical Profile in neonates and young infants. Indian Pediatrics 1985; 22; 333 - 8.

Table - 1 Demographic Feature of Study Participants.

\begin{tabular}{|l|l|l|}
\hline Age in Months & No of cases & Percentage \\
\hline $1-24$ & 107 & 71.33 \\
\hline $25-60$ & 23 & 15.2 \\
\hline $61-144$ & 20 & 13.3 \\
\hline Total & 150 & 100 \\
\hline Sex & No of cases & Percentage \\
\hline Males & 81 & 54 \\
\hline Females & 69 & 46 \\
\hline Total & 150 & 100 \\
\hline Social class & No of cases & Percentage \\
\hline 1 & 6 & 4 \\
\hline 11 & 47 & 31.33 \\
\hline 111 & 67 & 44.67 \\
\hline IV & 27 & 18 \\
\hline V & 3 & 2 \\
\hline Total & 150 & 100 \\
\hline
\end{tabular}

Table - 2 Nutritional status

\begin{tabular}{|l|l|}
\hline Nutritional status & No of cases \\
\hline Normal & 73 \\
\hline Malnutrion & $77(51.33 \%)$ \\
Grade I & $43(28.66 \%)$ \\
Grade II & $21(14 \%)$ \\
Grade III & $5(3.33 \%)$ \\
Under nutrition(<3rd centile & $8(5.33 \%)$ \\
weight for age b/w 6-12yrs) & \\
\hline
\end{tabular}




\section{ORIGINAL ARTICLE}

Table 3 Hydration Status of cases

\begin{tabular}{|l|l|}
\hline Severity of dehydration & No of cases \\
\hline No & $09(6 \%)$ \\
\hline Some & $120(80 \%)$ \\
\hline Severe & $21(14 \%)$ \\
\hline Total & $150(100)$ \\
\hline
\end{tabular}

Table - 4 Stool microscopy Characters.

\begin{tabular}{|l|l|}
\hline Stool Microscopy & No of cases \\
\hline Pus cells (> 10/HPF) & 47 \\
\hline RBC's & 21 \\
\hline No pus cells or RBC's & 82 \\
\hline Hookworm ova & 1 \\
\hline Cyst of E. Histolytica & 1 \\
\hline
\end{tabular}

Table - 5 Stool Culture Characters.

\begin{tabular}{|l|l|}
\hline Culture positive- Organisms isolated & No of cases \\
\hline Escherichia coli (42.66\%) & 64 \\
\hline Salmonella (3.3\%) & 5 \\
\hline Klebsiella (2.66\%) & 4 \\
\hline Shigella (25\%) & \\
\hline S. Dysentriae & 2 \\
\hline S. Flexnari & 1 \\
\hline Total (50.66\%) & 76 \\
\hline Culture negative (49.44\%) & 74 \\
\hline
\end{tabular}

